\title{
Dual-Frequency Two-Element Antenna Array with Suppressed Mutual Coupling
}

\author{
Yantao Yu, Lijun Yi, Xiaoya Liu, Zhaokai Gu, and Nadia Media Rizka
}

College of Communication Engineering, Chongqing University, Chongqing 400044, China

Correspondence should be addressed to Yantao Yu; yantaoyu@cqu.edu.cn

Received 21 September 2014; Accepted 12 December 2014

Academic Editor: Xinyi Tang

Copyright ( 2015 Yantao Yu et al. This is an open access article distributed under the Creative Commons Attribution License, which permits unrestricted use, distribution, and reproduction in any medium, provided the original work is properly cited.

\begin{abstract}
An efficient technique utilizing the defected ground structure (DGS) to suppress the mutual coupling effect of a dual-frequency microstrip antenna array is studied. The proposed dual-frequency DGS beneath two patches includes two circular split ring slots, each of which corresponds to one resonant frequency of the patches. The characteristic of the compact DGS is theoretically and experimentally investigated. The prototypes of the patches arrays with and without the proposed DGS are fabricated. Both the simulated and measured results show that the mutual coupling between array elements has been obviously reduced at the two operating frequency bands with the implementation of the proposed DGS structure.
\end{abstract}

\section{Introduction}

The multiple-input multiple-output (MIMO) antenna systems are widely used in new generation of wireless communication systems to accommodate higher data rates and provide increased capacity [1]. However, it is not an easy work to integrate multiple antennas in a small size wireless device while keeping a high level of isolation between antenna elements [2], especially for dual-frequency arrays. This is because the effects of mutual coupling between array elements become more severe when the separation between elements becomes smaller. The mutual coupling effect can cause significant system performance degradation, such as reduction in signalto-noise ratio and degradation of the synthesized far-field pattern. In addition, the high capacity offered by the MIMO system is reduced if the various signals at the receiver are correlated, where the correlation may arise from the mutual coupling between the transmitting and/or receiving antenna elements $[3,4]$. In order to remove or reduce the adverse effects of mutual coupling in compact antenna arrays, different techniques $[5,6]$ have been proposed in literature.

In signal processing, the coupling matrices [7] can be applied to the received signal vectors from the adaptive arrays to counter the effects of mutual coupling. The relation of the isolation and the array configuration of two nearby antennas in a cellular handset was studied in [8]. Parasitic scatters may also be exploited to reduce the mutual coupling effect in a MIMO array [9]. Various decoupling networks using reactive components [10] or $90^{\circ}$ or $180^{\circ}$ hybrid couplers [11, 12] have been proposed to increase the isolation between antenna ports. Recently, another effective approach to reduce mutual coupling is to use electromagnetic bandgap (EBG) structures [13] or defected ground structures (DGS) [14] to suppress the surface wave in microstrip substrates. The term "DGS" was first used by Kim and Park in describing a single unit of dumbbell-shaped defect in [15]. The application of DGS to reduce the mutual coupling between two adjacent microstrip patches was first shown in [16]. Most of the designs in literature including the aforementioned ones are for arrays with single operating frequency band. However, dual-frequency operation is preferred for many popular communication standards. Mutual coupling reduction for dual-frequency arrays has attracted many studies. Improvement on dualband isolation is achieved by using an array of printed capacitively loaded loops (CLLs) on the top side of the board and a complementary CLL structure on the ground plane [17]. However, this design is a bit complicated. A reconfigurable dual-band monopole array with high isolation is given in [18], which exploits the neutralization techniques and uses a switch to control the operating frequency band. The paper 


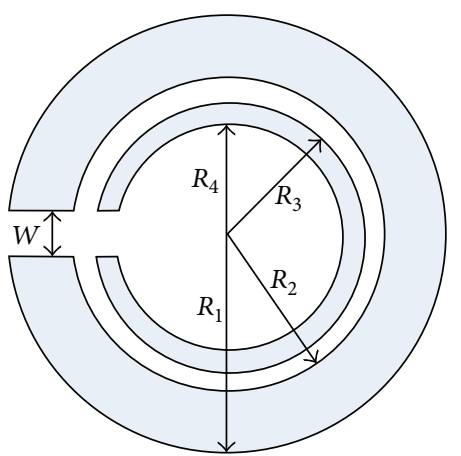

FIGURE 1: The geometry of the proposed defected ground structure.

[19] describes a procedure to achieve simultaneous decoupling and matching at two frequencies using decoupling network with series and parallel combination of inductors and capacitors.

In this paper, a compact design utilizing the defected ground structure to reduce the mutual coupling between array ports of a dual-frequency patch antenna array is proposed. The proposed dual-frequency DGS beneath two patches includes two circular split ring slots, each of which corresponds to one resonant frequency of the patches. The characteristic of the compact DGS is studied. The prototypes of the patch arrays with and without the proposed DGS are fabricated. Both the simulated and measured results are presented to show the effectiveness of the proposed structure in mutual coupling reduction at two frequency bands.

\section{The Dual-Frequency Defected Ground Structure}

The proposed defected ground structure is shown in Figure 1. Two cocentered circular split ring slots are etched on the ground plane of a dielectric substrate, which are the parts indicated in grey. The larger split ring slot has an outer radius of $R_{1}$ and an inner radius of $R_{2}$, while the smaller one has an outer radius of $R_{3}$ and an inner radius of $R_{4}$. The two split ring slots are resonant and create two stop bands. To study the characteristics of the DSG structure, a microstrip filter model is built in the EM simulator HFSS and the fabricated one is shown in Figure 2. The substrate is FR4 material with dielectric constant of $\varepsilon_{r}=4.4$ and thickness of $1.6 \mathrm{~mm}$, while the $50 \Omega$ microstrip line has a width of $3 \mathrm{~mm}$. The performance of the filter is studied by changing the dimensions of the split ring slots. Figure 3 shows the transmission coefficients of the filter with various values of $R_{1}$. It can be seen that the lower stop-band frequency decreases with the increase of $R_{1}$, while the upper stop-band frequency remains stable. The parameter $R_{2}$ has similar effect on the performance of the filter as $R_{1}$ as they determine the width of the larger split ring. Similarly, the transmission coefficients of the filter with different $R_{3}$ are plotted in Figure 4 . It is obvious that as $R_{3}$ increases, the upper stop-band frequency will decrease and the lower stopband frequency keeps unchanged. According to our study, the variation of $R_{4}$ also influences the upper stop-band much.

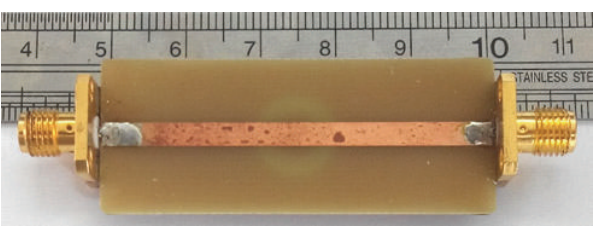

(a)

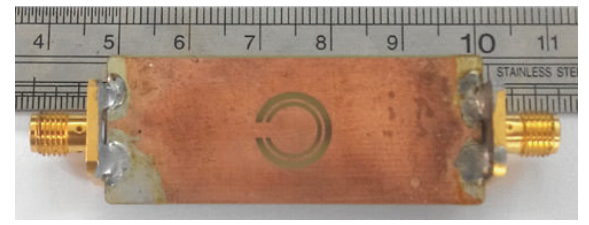

(b)

FIgUre 2: The fabricated microstrip filter with DGS. (a) Top view; (b) bottom view.

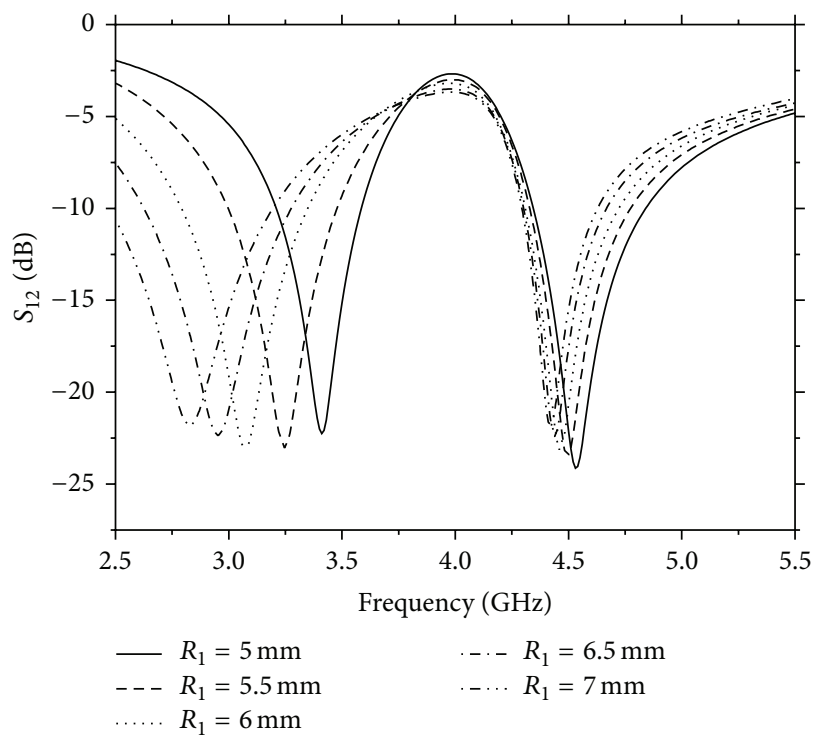

FIGURE 3: The transmission coefficient of the filter with variation of $R_{1}$.

By properly choosing the dimensions of the DGS structure, the desired band rejection characteristic can be obtained. Figure 5 shows the simulated and measured $S$-parameters of the band-stop filter with $R_{1}=5.2 \mathrm{~mm}, R_{2}=4.2 \mathrm{~mm}, R_{3}=$ $3.9 \mathrm{~mm}, R_{4}=3.1 \mathrm{~mm}$, and $W=2 \mathrm{~mm}$. It is obvious that the band-stop filter has two stop bands at $3.35 \mathrm{GHz}$ and $4.5 \mathrm{GHz}$.

\section{Patch Array with the Proposed DGS}

The proposed DGS structure can be implemented in a MIMO antenna array to reduce the mutual coupling. Two coaxial feed rectangular patch antennas with dual operating frequencies at $3.35 \mathrm{GHz}$ and $4.5 \mathrm{GHz}$ are designed, as shown in Figure 6 (without the ring slots). The substrate used for the patches is the same as the one used in filter design. The dimensions of the patch are $W_{1}=102 \mathrm{~mm}, L_{1}=80 \mathrm{~mm}$, $W_{2}=20 \mathrm{~mm}, L_{2}=25.2 \mathrm{~mm}$, and $W_{3}=6 \mathrm{~mm}, L_{3}=6 \mathrm{~mm}$. 


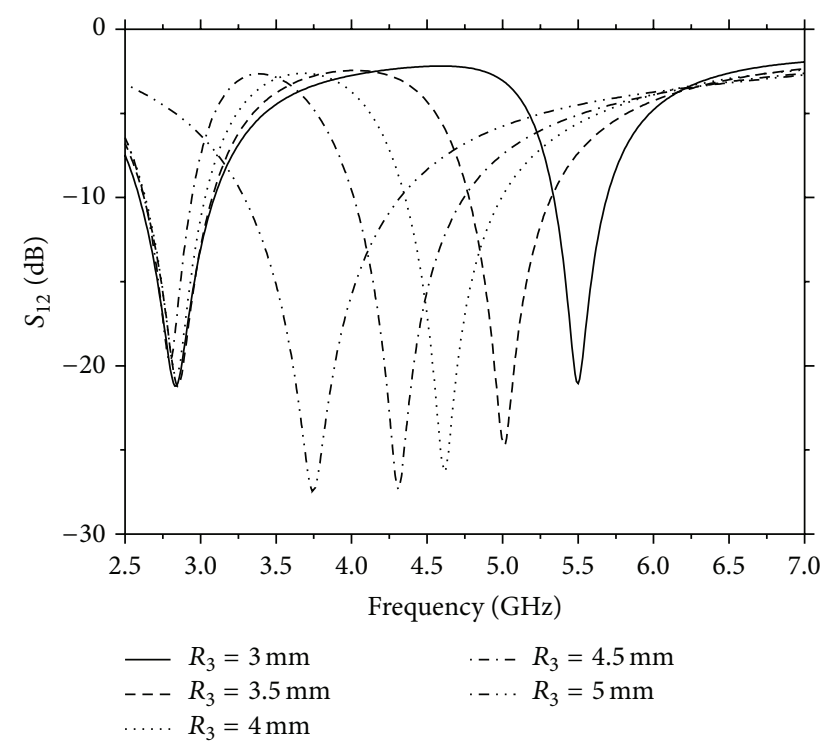

FIGURE 4: The transmission coefficient of the filter with variation of $R_{3}$.

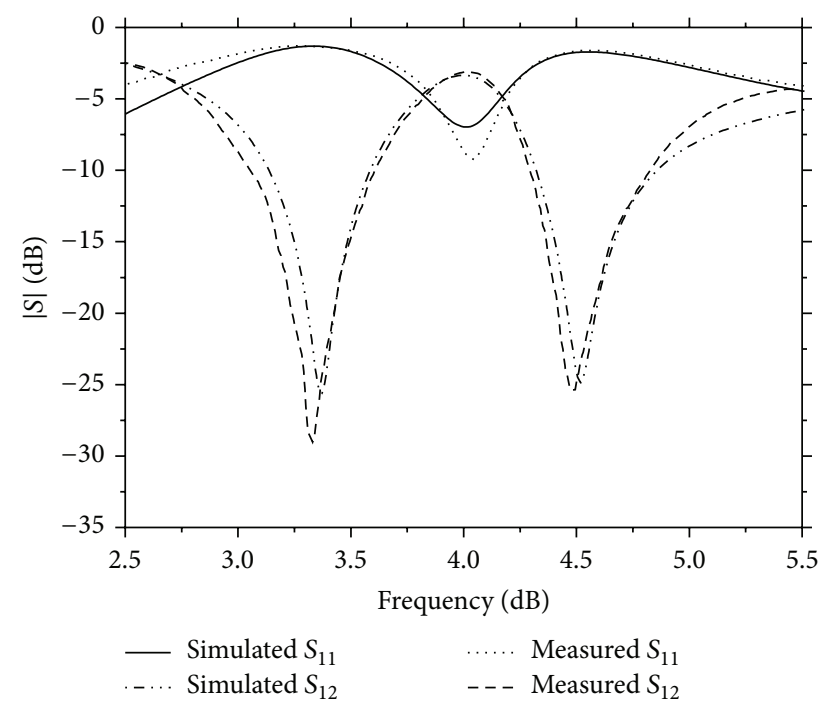

FIGURE 5: The $S$-parameters of the filter with optimized dimensions.

The edge to edge distance between the two patches is $d=10 \mathrm{~mm}$. The prototype of the patch array is shown in Figure 7(a). Figure 8 shows the simulated and measured $S$ parameters of the dual-frequency patch array. Although the two patches are not strictly symmetric about the center of the substrate, they have almost the same reflection coefficients in the design according to our simulation and measurement. Therefore, only $S_{11}$ and $S_{12}$ are plotted in Figure 8 . It can be seen from the plot that the array has two resonant frequencies at $3.35 \mathrm{GHz}$ and $4.5 \mathrm{GHz}$, respectively. The measurement agrees well with the simulation. It is also noted that the coupling coefficient is about $19 \mathrm{~dB}$ at $3.35 \mathrm{GHz}$ and $15 \mathrm{~dB}$ at 4.5 GHz.

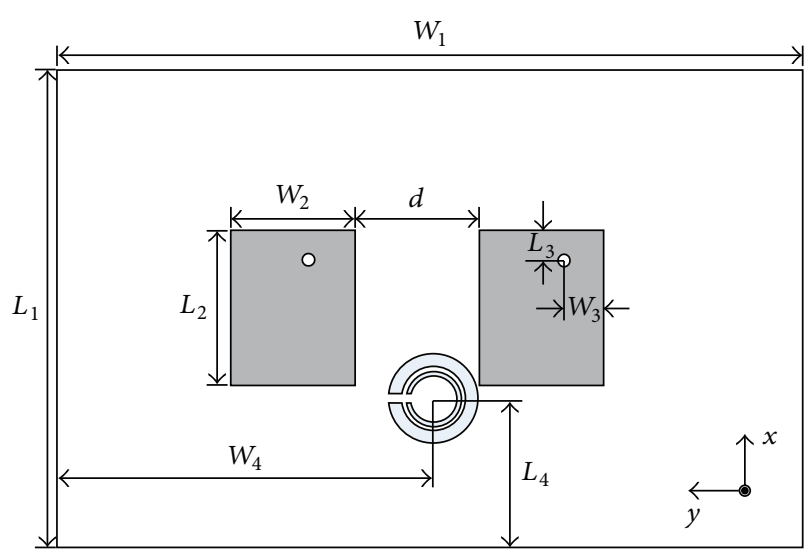

FIGURE 6: The geometry of the patch array.

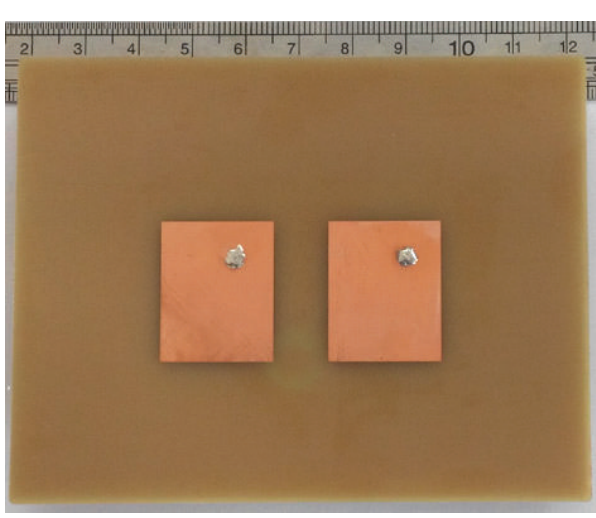

(a)

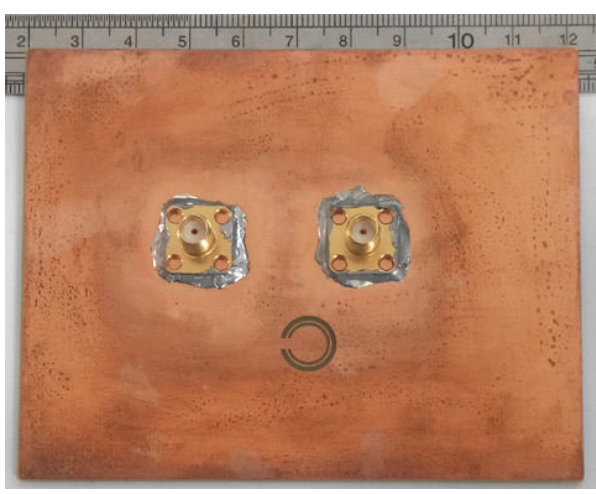

(b)

FIgURE 7: The prototype of the patch array. (a) Top view without DGS; (b) bottom view with DGS.

To reduce the mutual coupling, the proposed DGS structure is etched in the ground plane of the patches, as shown in Figure 7(b). The center position of the DGS is at $W_{4}=47.9 \mathrm{~mm}$ and $L_{4}=25.1 \mathrm{~mm}$. The $S$-parameters of the patch array with DGS are plotted in Figure 9. Since the two antennas are asymmetric after implementing the DGS in the ground plane, the $S_{11}$ and $S_{22}$ are not completely coinciding with each other, but the two patches are still operating in the two bands of the array. It can be seen from Figure 9 that the measured coupling coefficient remains below $-20 \mathrm{~dB}$ across 


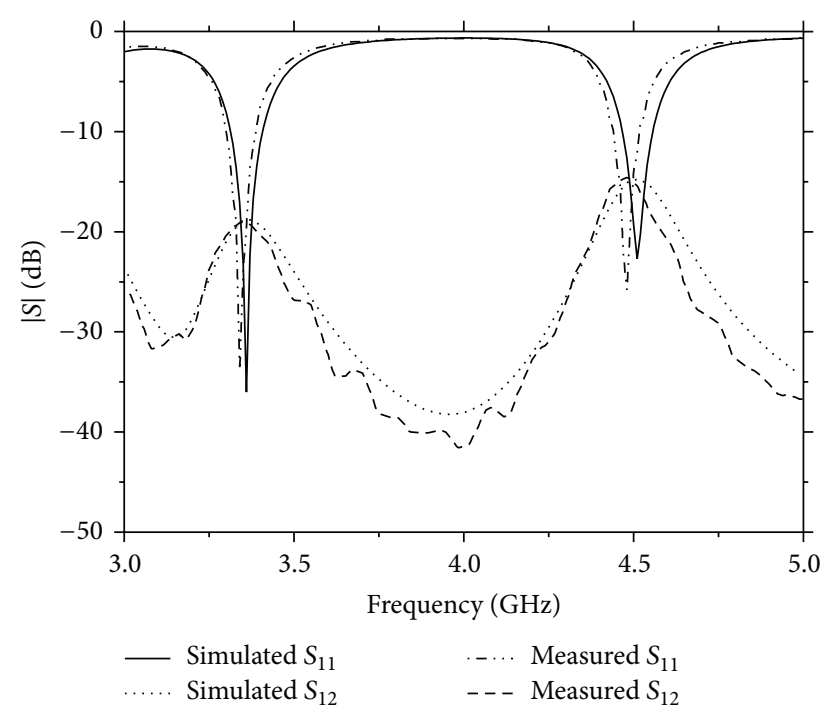

FIGURE 8: The $S$-parameters of the patch array without DGS.

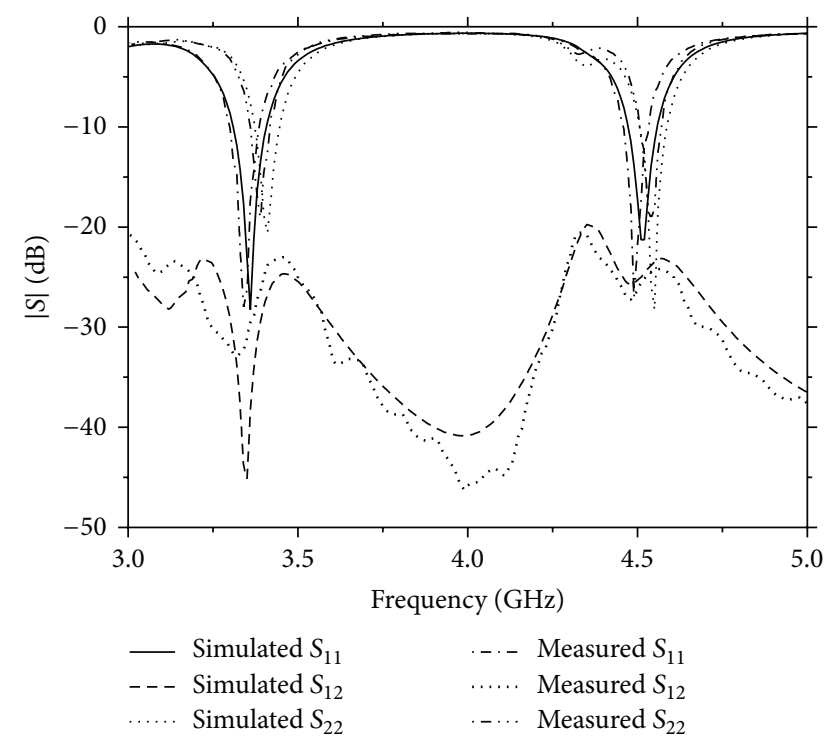

FIGURE 9: The $S$-parameters of the patch array with DGS.

the two frequency bands and has been reduced to $-33 \mathrm{~dB}$ at $3.35 \mathrm{GHz}$ and $-27 \mathrm{~dB}$ at $4.5 \mathrm{GHz}$. The simulated normalized radiation patterns of the patch array at $3.35 \mathrm{GHz}$ and $4.5 \mathrm{GHz}$ are plotted in Figures 10 and 11, respectively. The coordinate system is shown in Figure 6. It is obvious that the radiation patterns of the patch array remain in their general shapes before and after implementing the defected ground structure.

Correlation coefficient is an important parameter in MIMO performance evaluation. By assuming uniform external signal source distribution, the envelope correlation coefficient (ECC) based on the $S$-parameters of an array can be calculated using [20]

$$
\rho_{e}(1,2)=\frac{\left|S_{11}^{*} S_{21}+S_{12}^{*} S_{22}\right|^{2}}{\left(1-\left|S_{11}\right|^{2}-\left|S_{21}\right|^{2}\right)\left(1-\left|S_{22}\right|^{2}-\left|S_{12}\right|^{2}\right)} .
$$

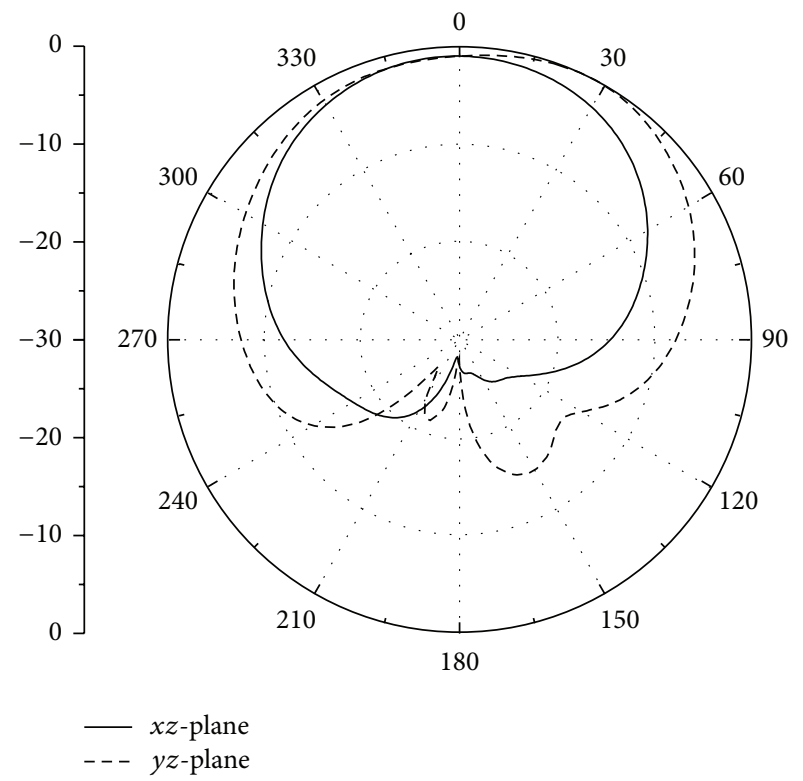

(a)

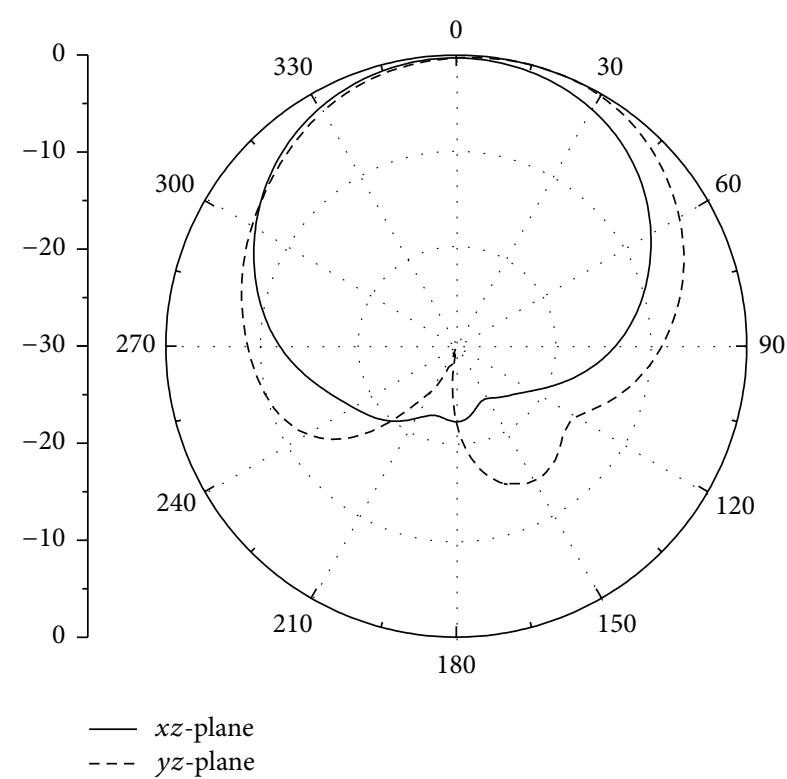

(b)

FIGURE 10: The simulated radiation pattern of the patch array at 3.35 GHz. (a) Without DGS; (b) with DGS.

If the antenna efficiencies are known in addition to the $S$-parameters, the correlation coefficients can be calculated using the method given in [21]. Figure 12 shows the envelope correlation of the patch array with and without DGS using (1). It can be seen that the envelope correlation in the frequency band of interest is very low, which means that the antenna array has good spatial diversity and is suitable for MIMO systems.

\section{Conclusion}

A compact defected ground structure using double circular split ring slots has been presented to reduce the mutual 


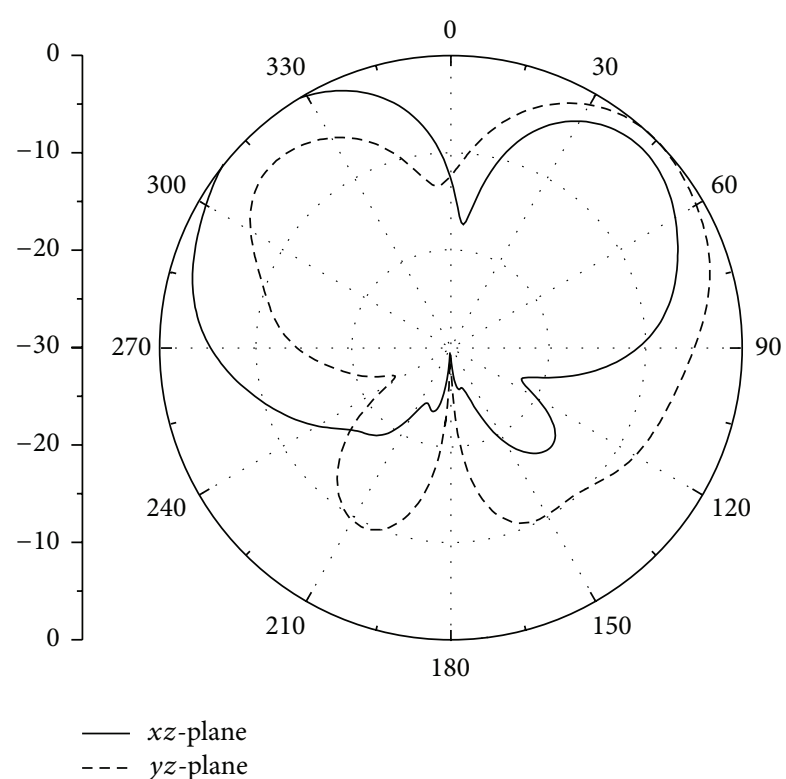

(a)

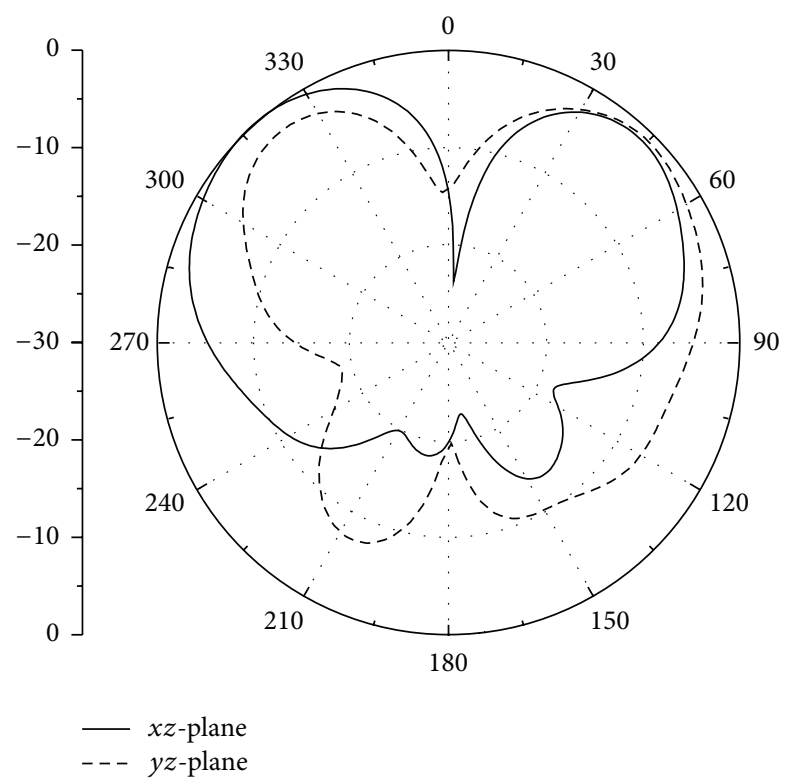

(b)

FIGURE 11: The simulated radiation pattern of the patch array at 4.5 GHz. (a) Without DGS; (b) with DGS.

coupling between array ports of a dual-frequency patch antenna array. The radii of the slots control the stop-band frequencies. The simulated and measured results of a twopatch array show that the mutual coupling effect between array elements has been obviously reduced. The resulted array has high port isolation and is suitable for MIMO applications.

\section{Conflict of Interests}

The authors declare that there is no conflict of interests regarding the publication of this paper.

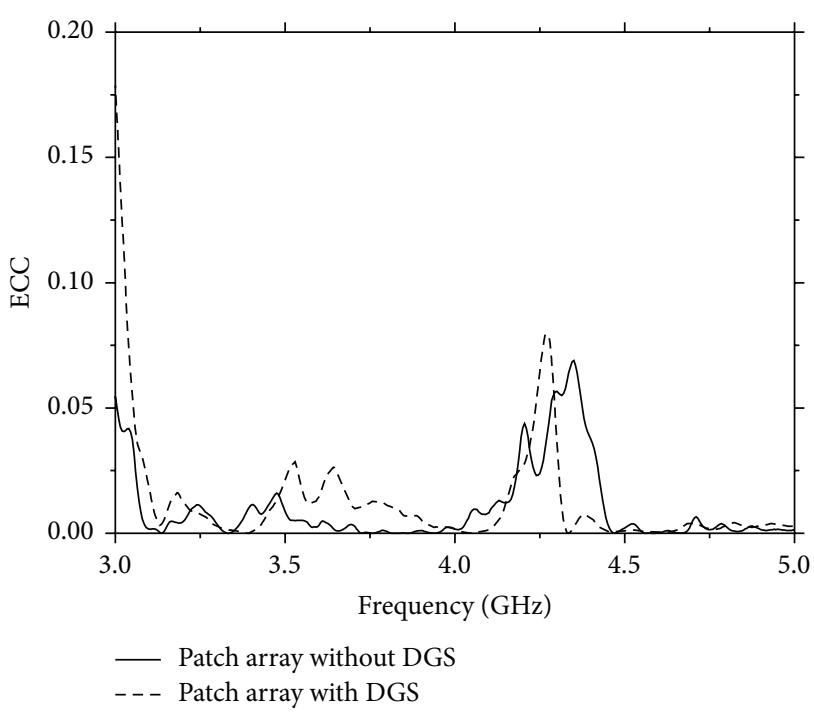

FIGURE 12: The measured envelope correlation of the patch array with and without DGS.

\section{Acknowledgments}

This work was supported in part by the National Natural Science Foundation of China (Grant 61101024), the Natural Science Foundation Project of CQ CSTC (Grant CSTC, 2011BB2070), the Fundamental Research Funds for the Central Universities (Grant nos. CDJZR12160013 and 106112014CDJZR165504), and the sharing fund of Chongqing University’s large-scale equipment (Grant 2013121556).

\section{References}

[1] M. A. Jensen and J. W. Wallace, "A review of antennas and propagation for MIMO wireless communications," IEEE Transactions on Antennas and Propagation, vol. 52, no. 11, pp. 28102824, 2004.

[2] A. C. K. Mak, C. R. Rowell, and R. D. Murch, "Isolation enhancement between two closely packed antennas," IEEE Transactions on Antennas and Propagation, vol. 56, no. 11, pp. 34113419, 2008.

[3] R. Janaswamy, "Effect of element mutual coupling on the capacity of fixed length linear arrays," IEEE Antennas and Wireless Propagation Letters, vol. 1, pp. 157-160, 2002.

[4] P. N. Fletcher, M. Dean, and A. R. Nix, "Mutual coupling in multi-element array antennas and its influence on MIMO channel capacity," Electronics Letters, vol. 39, no. 4, pp. 342-344, 2003.

[5] J. W. Wallace and M. A. Jensen, "Mutual coupling in MIMO wireless systems: a rigorous network theory analysis," IEEE Transactions on Wireless Communications, vol. 3, no. 4, pp. 13171325, 2004.

[6] H. T. Hui, "A practical approach to compensate for the mutual coupling effect in an adaptive dipole array," IEEE Transactions on Antennas and Propagation, vol. 52, no. 5, pp. 1262-1269, 2004.

[7] H. Steyskal and J. S. Herd, "Mutual coupling compensation in small array antennas," IEEE Transactions on Antennas and Propagation, vol. 38, no. 12, pp. 1971-1975, 1990. 
[8] Z. Li and Y. Rahmat-Samii, "Optimization of PIFA-IFA combination in handset antenna designs," IEEE Transactions on Antennas and Propagation, vol. 53, no. 5, pp. 1770-1778, 2005.

[9] Z. Li, Z. Du, M. Takahashi, K. Saito, and K. Ito, "Reducing mutual coupling of MIMO antennas with parasitic elements for mobile terminals," IEEE Transactions on Antennas and Propagation, vol. 60, no. 2, pp. 473-481, 2012.

[10] S. Dossche, S. Blanch, and J. Romeu, "Optimum antenna matching to minimise signal correlation on a two-port antenna diversity system," Electronics Letters, vol. 40, no. 19, pp. 1164$1165,2004$.

[11] J. C. Coetzee and Y. Yu, "Port decoupling for small arrays by means of an eigenmode feed network," IEEE Transactions on Antennas and Propagation, vol. 56, no. 6, pp. 1587-1593, 2008.

[12] T.-I. Lee and Y. E. Wang, "Mode-based information channels in closely coupled dipole pairs," IEEE Transactions on Antennas and Propagation, vol. 56, no. 12, pp. 3804-3811, 2008.

[13] F. Yang and Y. Rahmat-Samii, "Microstrip antennas integrated with electromagnetic band-gap (EBG) structures: a low mutual coupling design for array applications," IEEE Transactions on Antennas and Propagation, vol. 51, no. 10, pp. 2936-2946, 2003.

[14] C.-S. Kim, J.-S. Lim, S. Nam, K.-Y. Kang, and D. Ahn, "Equivalent circuit modelling of spiral defected ground structure for microstrip line," Electronics Letters, vol. 38, no. 19, pp. 1109-1110, 2002.

[15] C.-S. Kim, J.-S. Park, D. Ahn, and J.-B. Lim, "A novel 1-D periodic defected ground structure for planar circuits," IEEE Microwave and Wireless Components Letters, vol. 10, no. 4, pp. 131-133, 2000.

[16] D. Guha, S. Biswas, M. Biswas, J. Y. Siddiqui, and Y. M. M. Antar, "Concentric ring-shaped defected ground structures for microstrip applications," IEEE Antennas and Wireless Propagation Letters, vol. 5, no. 1, pp. 402-405, 2006.

[17] M. S. Sharawi, A. B. Numan, and D. N. Aloi, "Isolation improvement in a dual-band dual-element MIMO antenna system using capacitively loaded loops," Progress in Electromagnetics Research, vol. 134, pp. 247-266, 2013.

[18] Q. Luo, J. R. Pereira, and H. M. Salgado, "Reconfigurable dualband C-shaped monopole antenna array with high isolation," Electronics Letters, vol. 46, no. 13, pp. 888-889, 2010.

[19] J. C. Coetzee, "Dual-frequency decoupling networks for compact antenna arrays," International Journal of Microwave Science and Technology, vol. 2011, Article ID 249647, 3 pages, 2011.

[20] J. Thaysen and K. B. Jakobsen, "Envelope correlation in $(N, N)$ MIMO antenna array from scattering parameters," Microwave and Optical Technology Letters, vol. 48, no. 5, pp. 832-834, 2006.

[21] H. Li, X. Lin, B. K. Lau, and S. He, "Equivalent circuit based calculation of signal correlation in lossy MIMO antennas," IEEE Transactions on Antennas and Propagation, vol. 61, no. 10, pp. 5214-5222, 2013. 

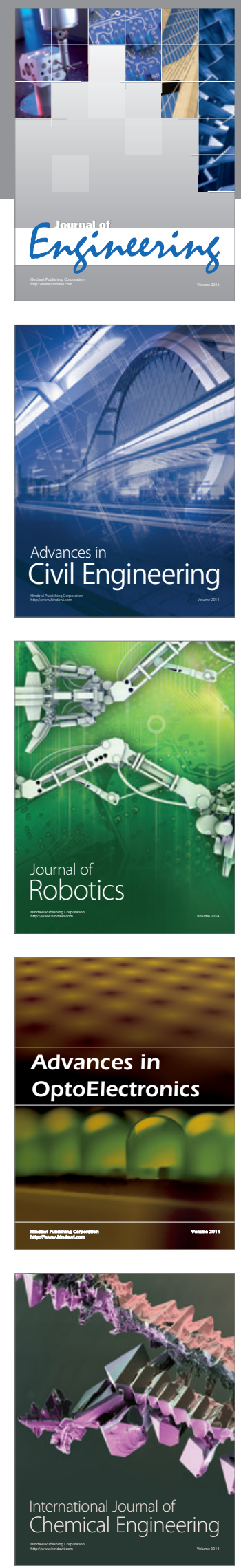

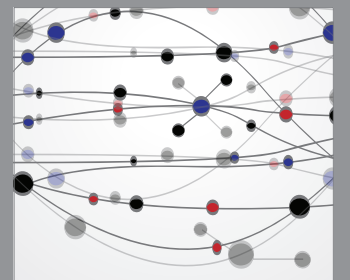

The Scientific World Journal
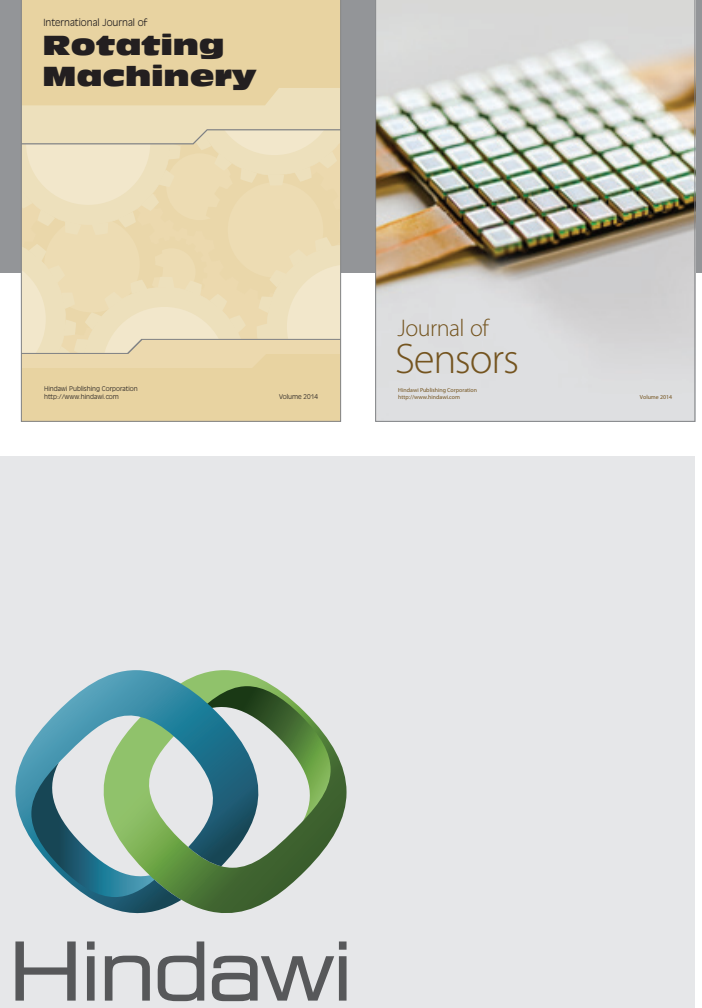

Submit your manuscripts at http://www.hindawi.com
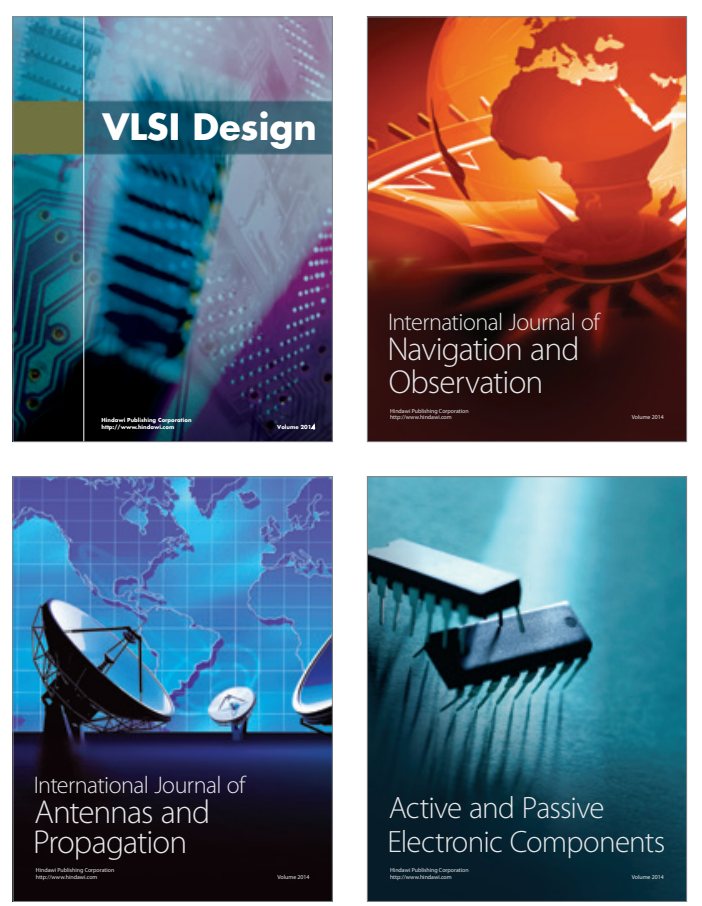
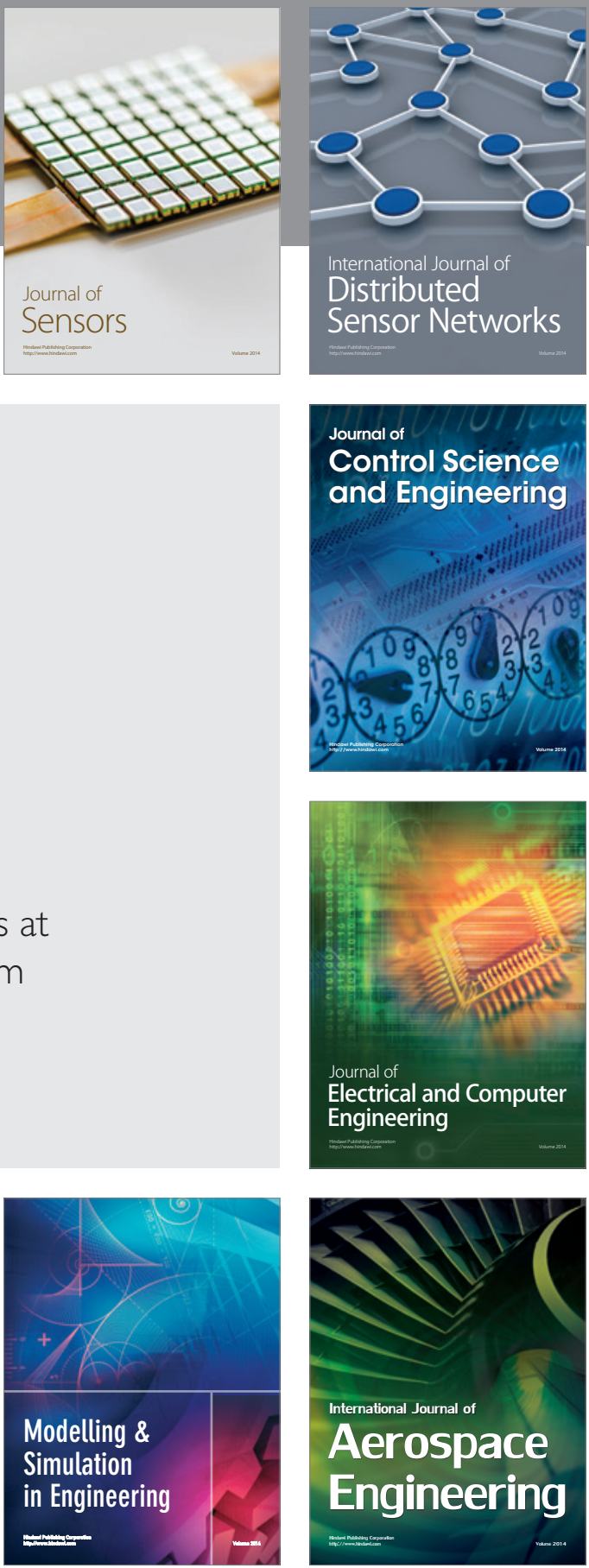

Journal of

Control Science

and Engineering
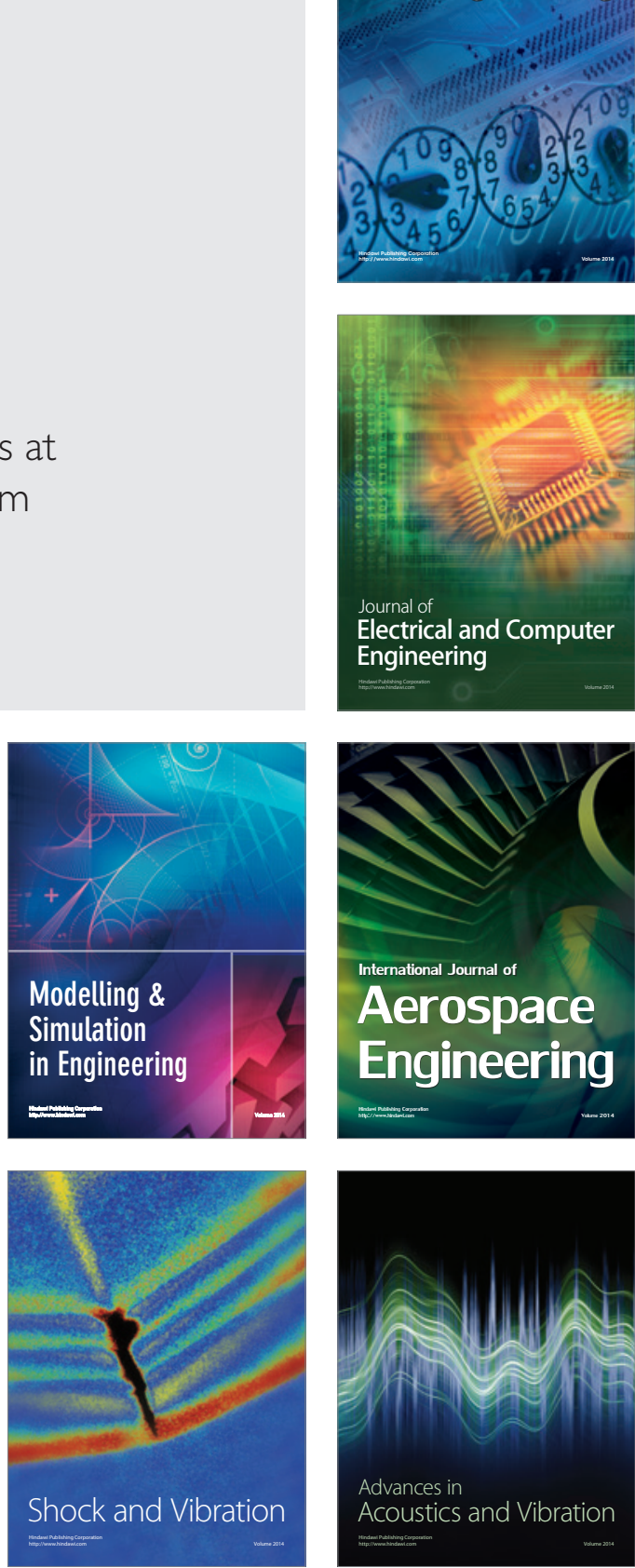